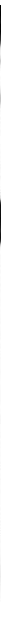

\title{
A FOTOGRAFIA COMO OBSERVAÇÃO NO ESTÁGIO SUPERVISIONADO EM FILOSOFIA
}

\author{
THE PHOTOGRAPH FOR OBSERVATION IN THE INTERNSHIP OF \\ THE TEACHING DEGREE IN PHILOSOPHY
}

\author{
André Luis La Salvia ${ }^{1}$ \\ Lilian Alvez Ortiz ${ }^{2}$ \\ Cibele de Cássia Nogueira Gennari ${ }^{3}$ \\ Marcio Nomura ${ }^{4}$ \\ Alexandre Henrique Luppe de Matos ${ }^{5}$ \\ Gabriel Valim Alcoba Ruiz ${ }^{6}$ \\ Janice Caovila ${ }^{7}$
}

Resumo: Dentro da perspectiva do estágio docente como campo de pesquisa, o presente artigo pretendeu refletir sobre as condições em que ocorre a proposta, a pesquisa e a realização de um estágio de observação na licenciatura em filosofia. A partir de um questionamento acerca das imagens clichês do ambiente escolar, optouse por problematizar a observação estimulando a produção de fotografias que escapassem do senso comum e captassem as singularidades da escola observada.

Palavras chaves: estágio; licenciatura; imagem; observação; filosofia.

Abstract: Within the perspective of the teaching internship as a field of research, this article intends to think on the conditions under which the proposal, the research and the accomplishment of an internship of observation in the teaching degree in philosophy occur. From a discussion on the clichés images of the school environment, we opted to problematize the observation by stimulating the production of photographs that escaped common sense and captured the singularities of the observed school.

\footnotetext{
1 Professor de Metodologia e Prática do Ensino de filosofia da UFABC, com pesquisa sobre Pedagogia do Conceito para Gilles Deleuze e Felix Guattari. E-mail: la.salvia@ufabc.edu.br.

2 Aluna da Licenciatura em filosofia da UFABC. E-mail: lilian.ortiz@aluno.ufabc.edu.br.

3 Aluna da Licenciatura em filosofia da UFABC. E-mail: cibele.gennari@gmail.com.

${ }^{4}$ Aluno da Licenciatura em filosofia da UFABC. E-mail: marcionomura@hotmail.com.

5 Aluno da Licenciatura em filosofia da UFABC. E-mail: alexluppe@hotmail.com.

${ }^{6}$ Aluno da Licenciatura em filosofia da UFABC. E-mail: gvalcobaruiz@gmail.com.

7 Aluna da Licenciatura em filosofia da UFABC. E-mail: caov@vol.com.br.

Revista Digital de Ensino de Filosofia - Santa Maria - vol.3. n. 1 - jan./jun. 2017.
} 


\section{Introdução}

Neste artigo, pretendemos problematizar a prática da observação nos estágios supervisionados obrigatórios para as licenciaturas em filosofia da Universidade Federal do $A B C$ (UFABC). Etapa tradicional nos estágios, a observação, regularmente, consiste na visita atenta às escolas, investigação do seu modus operandi e elaboração de um relatório.

Porém, com o objetivo de tornar o estágio mais significativo aos licenciados e à instituição escolar que os recebe, foi sugerido que discutíssemos o problema da persistência, no nosso imaginário, de imagens clichês que definem a escola como, por exemplo, um ambiente de confinamento, com grades e cadeados, ou local de desinteresse dos alunos e cansaço dos professores, através da produção de fotografias as quais fugissem dos lugares-comuns para destacar as singularidades daquela que fora observada.

A proposta de produzir fotografias que se distanciassem dos clichês comumente associados às escolas de ensino médio surgiu da necessidade de se repensar o papel formativo dos estágios na licenciatura em filosofia e de promover conhecimento a partir de práticas diferenciadas. Isso porque a formação de professores de filosofia no Brasil é tradicionalmente marcada pelo processo conhecido como " $3+1$ ", ou seja, depois de se concluir 0 bacharelado, complementa-se a formação com as disciplinas voltadas ao ensino, o que muitas vezes ocorre nos departamentos de educação, não ficando sob responsabilidade dos docentes da área.

Amurabi Oliveira e Vilma Barbosa descrevem a situação das ciências sociais que, a nosso ver, seria semelhante na filosofia:

Nas universidades brasileiras, esse modelo ainda não foi totalmente superado, já que disciplinas de conteúdo específico, de responsabilidade dos institutos básicos, continuam precedendo as disciplinas de conteúdo pedagógico e articulando-se pouco com elas, as quais, geralmente, ficam a cargo apenas das faculdades ou centros de educação. Além disso, o contato com a realidade escolar continua acontecendo, com mais freqüência, apenas nos 
momentos finais dos cursos e de maneira pouco integrada com a formação teórica prévia. (2013, p. 142).

Talvez um dos resultados dessa situação seja a pequena produção de pesquisa na área de estágio supervisionado em filosofia. Nesse sentido, o presente artigo visa a contribuir com as reflexões sobre estágios supervisionados ao propor uma experiência diferente, analisando os seus pressupostos e resultados.

Dentro dessa perspectiva, Oliveira e Barbosa afirmam que o estágio deve ser planejado e problematizado em um processo crítico, já que

\begin{abstract}
devido a sua intermitência no currículo escolar, atrelada à ausência de um número significativo de pesquisas sobre a temática, não possui um vasto conhecimento acumulado em torno de suas metodologias do ensino, produção e utilização de materiais didáticos, elaboração e correção de atividades avaliativas próprias para a educação básica. (2013, p.148).
\end{abstract}

No que se refere especificamente ao Estágio Supervisionado I, considerado momento inicial de observação, o primeiro procedimento foi a tentativa de tematizar os clichês presentes na imagem que fazemos das escolas. Tematizar as imagens já internalizadas para não reproduzi-las, através de um olhar distante. Desse modo, não queríamos mais considerar o estágio como mera observação, descrição e crítica de acontecimentos na escola e nas salas de aula.

A observação foi entendida como um processo ativo de produção de fotografias. Tomamos como fundamental a aproximação do cotidiano escolar com a reflexão e problematização dos dados encontrados, concebendo-os como pesquisa que busca ser significativa aos licenciandos e à comunidade escolar. Nesse sentido, a proposta foi tirar fotos e devolvê-las à comunidade escolar em forma de exposição.

Para realizar tal projeto de estágio, foi necessário firmar parceria com uma única escola e estabelecer um contato prévio com o coordenador, Max Douglas do Amorim, e com os professores, explicando-lhes o propósito da experiência fotográfica. Decidiu-se pela Escola Estadual Anésia Loureiro da 
Gama que fica a poucas quadras da Universidade Federal do $A B C$ (UFABC), em São Bernardo do Campo. No total, seis alunos desenvolveram a proposta de estágio.

O presente artigo é composto por fragmentos dos relatórios elaborados por seis alunos que desenvolveram a proposta de estágio. Os trabalhos foram organizados pelo professor orientador da proposta para configurar este artigo como resultado dos conhecimentos mobilizados.

\section{Enunciando o problema}

Na observação da escola, não queríamos desenvolver aquilo que Anderson Tibau (2001) chamou de um "certo ofício do estagiário", uma série de práticas como "observar umas aulas", "sentar no fundo da sala para não atrapalhar", "corrigir alguns cadernos (na escola) e trabalhos (na faculdade)", "solicitar a assinatura do professor na folha de presença", "levantar dados provenientes do relatório", "cumprir uma carga-horária", "simular uma aula prática", "montar a pasta".

Dessa forma, foi sugerido aos licenciandos um olhar diferente para a escola, mais investigativo, curioso, que não naturalizasse os fenômenos educacionais. Para tanto, pretendia-se estimular a produção de fotografias como uma das formas de promover esse outro olhar.

A filosofia é muitas vezes definida como aquela que surge da admiração, ou do espanto, com a realidade, gerando ferramentas conceituais para dar conta de tal atitude. Então, nada mais coerente com a prática filosófica que um estágio de observação que desnaturalize o olhar comum e se coloque na condição de apreciar com o que pode passar despercebido no cotidiano.

A proposta de trabalho inicial na Escola Estadual Anésia Loureiro Gama era a de observar e repensar o espaço escolar fugindo dos clichês e estereótipos mais comuns associados ao referido espaço. Essa mudança de ótica motiva o surgimento de novas facetas da escola e com isso novas Revista Digital de Ensino de Filosofia - Santa Maria - vol.3. n.1 - jan./jun. 2017. 
reflexões e campos de estudo se abrem à análise, partindo da premissa de que nossa visão do ambiente escolar está polvída por certas noções que podem não fazer jus à situação vivida por aqueles que lá estão.

Para esse exercício do observar mais admirado, foi sugerida uma atividade de produção de fotografias. Nesse sentido, acompanhamos a proposta de Anelice Ribetto e Valter Filé:

a primeira intenção de trabalhar com essa produção como centro do estudo dessa disciplina foi fotografar - no estágio aquilo que interrompa nossa tranquilidade de olhar, fazendonos ver (pensar, sentir) coisas que até então não tínhamos visto (pensado, sentido), ou seja, a produção de imagens como exercício de alteridade. (2014, p.228)

Os pesquisadores citados acima propuseram um exercício de desnaturalizar o olhar por acreditarem que ele já está encoberto de explicações pré-concebidas que permitem atingir 0 outro apenas indiretamente, por meio da reprodução burocrática dos relatórios, e

O que temos visto ao longo dessas experiências é uma recorrente prática discursiva e um repetitivo olhar que se empenha em nomear rápida e quase que automaticamente esses espaços como espaços de falta. Antes mesmo de se produzir o encontro entre nós - alunos e professores da universidade e das escolas - já está dito, já está certo aquilo que vamos encontrar e até as teorias que irão fundamentar nosso dizer faltoso. Entendemos que esse processo invalida a possibilidade de que "alguma coisa nos passe, nos aconteça" nesse encontro, no estágio. Se já sabemos o que vamos encontrar, $O$ estágio se transforma só em um trâmite burocrático de produção de relatórios que precisam apenas ser carimbados e legitimados no final do período. (2014, p. 231)

Desse modo, há necessidade de se promoverem rotas de observação novas e criativas da cena pedagógica as quais problematizem os clichês que eventualmente tomam o lugar de reflexões críticas.

Durante os encontros de orientação do estágio, foi preciso pensar nos clichês presentes nas mídias e na própria visão que os licenciandos foram construindo como alunos. Começar, portanto, problematizando o fato de que, como eles frequentam escolas desde crianças, as convicções sobre suas 
características podem tender a se tornarem clichês. Por isso, antes de observar, é necessário se lembrar das imagens já construídas da escola durante o processo de formação como discente e retomar tal experiência para questioná-la, desnaturalizando o olhar.

Foi importante também nas orientações propor alguns procedimentos para ajudar no processo de observação, como conversar com as pessoas para compreender qual valor dão a determinados aspectos da escola; frequentar os seus diferentes espaços e, aos poucos, entender as práticas ali desenvolvidas; atentar para as expectativas que a instituição tem quanto à sua participação.

Outros aspectos precisam ser destacados e problematizados pelo olhar de cada estagiário, buscando construir um diagnóstico da escola capaz de desmistificar estereótipos e visões generalizantes acerca da sua rotina e práticas desenvolvidas. Nesse sentido, é importante levar em conta à imagem que a comunidade escolar possui da própria escola, pois os detalhes que fogem aos clichês e ao olhar acostumado podem já estar acontecendo.

As reuniões de orientação e as visitas à escola foram acompanhadas da produção de fotos a partir dos impactos das vivências e problematizações. Essa etapa foi preparada pelas anteriores como potencializadora de novos olhares. Então, durante os encontros de orientação do estágio, as imagens conforme eram realizadas, foram armazenadas em um grupo fechado no site facebook.com. Tornaram-se objeto de discussão, através da qual tais fotografias, vez ou outra, remetiam a algumas ideias novas, como se, em vez de serem afetados e construírem uma imagem, esta se encontrava agora na posição de afetar e fazer pensar.

\section{Os clichês escolares}

O senso comum guarda da escola uma imagem hostil, qual seja, as grades ou muros garantem o confinamento dos alunos por um número de horas rigorosamente preenchidas com atividades que se pretendem educativas e formadoras àqueles que ali se encontram. A disciplina é imposta Revista Digital de Ensino de Filosofia - Santa Maria - vol.3. n. 1 - jan./jun. 2017. 
à medida que os alunos são impedidos de se associarem, devendo resolver provas orais ou escritas separadamente, ou quando são direcionados a brincar em horários fixos e segundo regras pré-definidas. Auno é aquele que se deve adequar às normas que lhe são impostas pelas autoridades escolares.

Todos esses fatores desmotivam o discente, levando-o a um descomprometimento com os estudos e a uma revolta contra as pessoas que são eleitas como suas autoridades diretas, a saber, os professores.

Contudo, tais características da instituição de ensino não devem ser universalizadas, visto que em algumas escolas isso não se realiza em sua totalidade. Apesar de possuírem grades e horários rígidos, algumas delas conseguem escapar da imagem clichê que lhes é repetidamente atribuída.

No que se refere às atividades de um licenciando em filosofia, a observação passiva em sala de aula é uma característica marcante dos estágios supervisionados, uma espécie de vicio que deixa de explorar todo o seu potencial formativo à futura profissão. Para as licenciaturas em filosofia, como diz a pesquisadora Heuser, trata-se de "muralhas da China" as quais atravancam a reflexão da teoria e da prática na docência e, se não problematizadas, prejudicam as "experiências de invenção filosófica de si e da docência em Filosofia" (2010, p.19). Uma das muralhas, podemos apontar, seria o fato de as representações cotidianas das escolas terem virado clichês e, por isso o desafio de produzir imagens que evitam tais lugares-comuns configurou-se como estímulo desta pesquisa.

As fotos deveriam marcar o caráter de rompimento com o que Ribetto e Filé chamam de "mesmidade" escolar. Poderiam mostrar as "possibilidades de potência de uma escola que aparece, muitas das vezes, como (in)visível no olhar do aluno - e que irrompe como acontecimento" (2014, p. 227). Assim, as fotos revelariam certo estranhamento das imagens e convivência escolares quase sempre assinaladas pela sua representação disciplinar como prisão. Não significa esconder que exista tal dinâmica autoritária, mas que essa ideia ou representação não encubra todas as suas características, possibilidades, 
novos olhares para entender que há pessoas que vivem ali, que passam, que transformam o lugar, em suma, que há vida, diferença, complexidade acontecendo.

Dizem os pesquisadores que

\begin{abstract}
"estagiar" pode ser uma experiência de estranhamento e, como tal, pode ser também a experiência de relação com esse estranhamento. Assim, o fundamental não são nossas habilidades como coletores de dados, caçadores de evidencias, especialistas em tratar, relatar e sintetizar informação, mas aquilo que nos nutre e nos prepara para viver a experiência [do estagio] e para perguntar sobre as questões pedagógicas das experiências que buscamos compreender. (...) O que nos interessa, nessa empreitada, é questionarmos o olhar acostumado (RIBETTO; FILÉ, 2014, p. 232)
\end{abstract}

Assumindo referida posição, a saber, a de encontrar novas narrativas na esfera acadêmica que ultrapassem ideias clichês a seu respeito, não se está negando a realidade destas. Não se nega, por exemplo, a existência da forte relação entre o cenário escolar e a disciplina em seu âmbito repressivo, imagem tão desgastada e já sabida por todos.

Um dos referencias teóricos para a elaboração desse olhar alternativo foi uma experiência organizada na Universidade do Estado do Rio de Janeiro (UERJ) onde alunos, em uma experimentação etnográfica, investigaram e relataram o ambiente escolar em suas produções fotográficas, partindo de um olhar antropológico. Quando este é assumido, pretende-se construir compreensões acerca de culturas e identidades, utilizando a produção imagética como meio de informar etnograficamente, tendo em vista, no nosso caso, o direcionamento para a efetuação do não clichê. Ao registrar novos olhares acerca da escola, ou seja, registrar o que está presente no outro, mas que ainda não é visto pelo sujeito, pode-se reconhecer a si mesmo com um olhar viciado, construído por teorias estudadas, experiências de alunos e préconceitos com relação à instituição escolar.

Tal vício do olhar foi objeto de tentativa de desconstrução no decorrer do estágio, não uma proposta de anular qualquer olhar já anteriormente construído, pretendendo uma visão neutra sobre a escola, dado que isso seria Revista Digital de Ensino de Filosofia - Santa Maria - vol.3. n.1 - jan./jun. 2017. 
impossível. Buscamos, em lugar disso, uma transgressão desse olhar aprendido, ao desestruturá-lo, visando a reconstruí-lo a partir de novas estruturas, atividade um tanto filosófica se considerarmos o papel "desnaturalizador" da filosofia. Esta saída do lugar-comum vem sempre acompanhada de um espanto, de um afeto - fundamental à prática filosófica, assim como diz Platão: "É verdadeiramente de um filósofo esse phátos - o espanto; pois não há outra origem imperante da filosofia que este".

Espantar-se com a realidade foi uma das etapas do estágio de observação. A outra era a produção de fotos as quais deveriam estar livres dos clichês. Nesse sentido, recorremos aos filósofos Gilles Deleuze e Felix Guattari que caracteriza esse deslocamento da posição comum como uma saída do caos, necessária para que possamos ver o novo:

Um pintor não pinta sobre uma tela virgem, nem o escritor escreve sobre uma página branca, mas a página ou a tela estão já de tal maneira encobertas de clichês preexistentes, preestabelecidos, que é preciso, de início, apagar, limpar, laminar, mesmo estraçalhar para fazer passar uma corrente de ar, saída do caos, que nos traga a visão. (DELEUZE;GUATTARI, 1992, p.261)

Precisávamos saber o que era clichê para combatê-lo. Deleuze, em seu livro Imagem-tempo, ensina que uma imagem clichê é uma repetição de signos, de enquadramentos que permitem o fácil reconhecimento por parte dos espectadores. Segundo o filósofo, as imagens são construídas a fim de que eles observem os elementos escolhidos pelo seu criador para serem percebidos. É dessa forma que, conforme Deleuze, fomos domesticados. E sendo domesticados por imagens, percebendo "sempre menos, percebemos apenas o que estamos interessados em perceber, ou melhor, o que temos interesse em perceber, devido a nossos interesses econômicos, nossas crenças ideológicas, nossas exigências psicológicas" (DELEUZE, 2005, p. 31). É nesse sentido que o autor diz estarmos vivendo uma civilização do clichê, não da imagem. É dessa forma, dentro dessa civilização, que fomos nos acostumando a certas imagens, tornando toda experiência algo repetitivo.

Civilização da imagem? Na verdade uma civilização do clichê, na qual todos os poderes têm interesse em nos encobrir as imagens, não Revista Digital de Ensino de Filosofia - Santa Maria - vol.3. n.1 - jan./jun. 2017. 
forçosamente em nos encobrir a mesma coisa, mas em encobrir alguma coisa na imagem. Por outro lado, ao mesmo tempo, a imagem está sempre tentando atravessar o clichê, sair do clichê. (DELEUZE, 2005, p. 32)

Para o nosso caso especifico, identificamos como clichês, após algumas análises de fotos já tiradas, a escola como prisão, cenário de autoridade, ou de excessiva permissividade, ambiente falido ou ainda com posição missionária, isto é, "salvação" dos jovens e da sociedade. Referidas fotos, embora muitas vezes paradoxais, mostravam visões consolidadas dos julgamentos prévios, de mesmidade, transpostas para o ambiente escolar, perpassando todas as suas relações, encobrindo, de antemão, possibilidades. Entendemos que elas poderiam simplificar e/ou empobrecer as possíveis análises ou mesmo vivencias diferentes que seriam ali construídas. O objetivo, então, de nossas fotos era o de tentar revelar singularidades, algo invisível para os que olham com as visões preconcebidas de sempre. Aceitamos tal desafio. Entramos na escola. Vivemos seu ambiente. Vimos suas relações. Fotografamos.

Outro referencial teórico nas reuniões de orientação foi a discussão a respeito do que significa documentar. Para auxiliar tal debate estudamos as ideias e o documentário "Boca de lixo" de Eduardo Coutinho. Analisamos a impossibilidade de se construir um olhar neutro, e por isso nossa tentativa era a de reestruturar o olhar. Segundo Coutinho, a própria presença de uma máquina (câmera fotográfica, filmadora etc.) já é suficiente para interferir no nível de realidade, no agir espontâneo das coisas, pois quando se enquadra uma ou duas delas em detrimento de outras já se constrói uma ideia enviesada que interferirá no real.

Deparamo-nos, também, com a impossibilidade de identificação entre as nossas imagens e o próprio real na medida em que elas revelam o caráter de representação (re-apresentação) do real por meio da leitura daquele que fotografa. Não é que tenhamos registrado a verdade da escola. Como afirma Eduardo Coutinho, refletindo sobre o documentário, não é que tenhamos captado "a vida como ela é", "as relações como elas são". O cineasta destacava que: 
Na verdade, no documentário americano, mesmo em seus melhores exemplos, passa-se como se aquilo que estivesse acontecendo fosse absolutamente real. Mas o documentário, ao contrário do que os ingênuos pensam, e grande parte do público pensa, não é a filmagem de verdade. Referindo-se que possa existir uma verdade, o que o documentário pode pressupor, nos seus melhores casos - e isso já foi dito por muita gente -, é a verdade da filmagem. (OHATA, 2014, p. 23).

A questão era analisar as fotos de forma tão metalinguística como os documentários do Coutinho. Elas não eram a verdade, mas o nosso recorte para problematizar $\circ$ estatuto das imagens previamente associadas às escolas. Parte de nossas intenções era que as pessoas vissem as fotos e estranhassem, pensassem as realidades, no fundo, construídas e, dessa forma, pudessem desconstruí-las, problematizá-las.

No caso da visão comum sobre a escola, de que forma a montagem das imagens que temos dela modela conclusões que tiramos a respeito do ambiente escolar? A imagem estereotipada da "escola prisão" ou da escola como local de "salvação" dos jovens prevalece perante uma análise mais aprofundada do que seriam, de fato, as interações entre os alunos, professores, direção e o ambiente. Tal imagem viciada simplifica e empobrece possíveis reflexões acerca das intensas relações que podem ocorrer. Por isso, nos propusemos a encontrar e fazer imagens da escola, o que envolve um grande esforço, dado que sempre há muito trabalho para se descobrir ou mesmo criar o novo.

O uso da fotografia educava o olhar. Não bastava pensar numa ideia não clichê, tratava-se de representá-la numa imagem, o que se mostrou muito custoso. Antes de pegar o celular para fotografar, era importante já ter em mente, uma ideia que se realizaria na imagem. Mas na dificuldade de encontrar as que não fossem clichês do ambiente escolar, algumas fotografias foram produzidas ainda dentro do senso comum. Contudo, essas imagens alimentaram nossas discussões e reflexões a respeito de quais seriam clichês e quais despertariam um novo olhar sobre a escola. 


\section{A escola e as impressões}

Segundo dados oficiais, a Escola Estadual Professora Anésia Loureiro Gama começou a funcionar no ano de 1962 como Grupo Escolar "Vila Império". Recebeu o nome atual em homenagem à educadora Anésia Loureiro Gama que nasceu em 4 de junho de 1890, na cidade paulista de Tatuí. Localizada em bairro de classe média em São Bernardo do Campo, possui locais adaptados a alunos com deficiências. A presença de tais alunos, assim como toda a instalação e recurso humano necessário, já é algo positivamente fora dos padrões. Cabe aqui uma ressalva: a escola não contava, à época, com professor para o atendimento educacional especializado, previsto em lei para alunos com deficiência. O recurso existente era o cuidador que, embora necessário, não é suficiente para esse trabalho. $\bigcirc$ prédio inteiro encontra-se construído em piso térreo. No seu entorno há várias espécies de plantas, mas o acesso a este espaço arborizado é restrito já que as saídas planejadas para as salas foram fechadas. As salas são pequenas.

As visitas à escola Anésia proporcionaram momentos de problematização intensa: desde a iluminação dos ambientes, presença de imagens de tradição católica até o comportamento dos alunos sem deficiências perante aqueles com deficiências. Diversas foram as situações em que a visão imediata, proveniente do senso comum, prevaleceu. Foi extremamente difícil observar alunos e fazer considerações a respeito da escola em si, as quais não estivessem deturpadas com pré-conceitos e clichês. A tentativa de revisitá-la nos mostrou o quanto nossa visão é direcionada para tudo o que ouvimos e lemos sobre ela, fazendo-nos tirar conclusões que pensamos ser nossas, mas que não são. Essa "desinfecção" da olhar passa pelo convívio com professores e alunos, e a fotografia nos ajudou a perceber detalhes que inicialmente nosso olhar não captou.

Ao entrar na escola, foi notável, nos primeiros dias, a frase "vamos nos comportar como se não estivéssemos aqui". Os alunos não só percebiam que havia um estranho ali, como simulavam, de forma estereotipada, seus próprios comportamentos. Passado algum tempo, notou-se atitude diferente deles, não 
mais natural (era justamente essa ideia que queríamos reconstruir), porém mais espontânea. Alguns alunos, no começo, mais agitados deixaram de ser, enquanto outros mais contidos passaram a participar mais da aula. Para os professores, "estes eram os alunos de verdade", ou seja, aquele era o comportamento que eles observavam normalmente durante as aulas. Com isso, como saber qual seria o comportamento "verdadeiro" dos alunos em sala de aula?

Houve uma semana de jogos escolares, os quais constavam de várias modalidades, disputadas pelos alunos e alunas das diferentes séries. Foram três dias de movimento intenso permitindo uma leitura do cotidiano escolar em um cenário mais descontraído. Foi possível conversar com alunos e professores e observar algumas relações estabelecidas.

Alguns alunos estavam ali para ficar com os amigos. Não estavam jogando nem torcendo, apenas se divertindo. Tais momentos de expressões de afetos envolviam também os professores. Uma das conclusões foi o quanto esses espaços de liberdade fazem diferença para o percurso dos jovens. Representavam uma estratégia de sobrevivência em um cotidiano marcado por regras e limites estreitos. Talvez se constituam como respiradouros diante das pressões escolares e das escolhas. Parte da observação se deu nos dias seguintes ao da realização do ENEM, e testemunhamos a tensão dos alunos do terceiro ano do ensino médio: sua necessidade de falar sobre o que vivenciaram, desabafar...

Para o processo formativo, esta proposta trouxe como desafio, além de aprender a operar com as ferramentas para a produção, arquivo e disponibilização de imagens, o de utilizar a fotografia como uma linguagem e, por meio dela, buscar traduzir e compreender as experiências vivenciadas na escola.

Em uma primeira etapa, produziram-se imagens de tudo o que chamava a atenção. À medida que se familiarizava com a técnica e com o 
ambiente, podia-se apurar o olhar, selecionando as tomadas, observando ângulos distintos para tentar compreender o contexto e a cultura da escola.

Algumas dessas "potencialidades" foram retratadas nas fotos. Talvez elas tenham a capacidade, se não para imediatamente romper com os clichês escolares, de propor uma imagem de diferença, de nova existência do que significa a vida escolar. Elas, de alguma forma, podem deixar suas marcas, provocando o efeito de choque diante de sua imprevisibilidade, abalando algumas certezas, afetando de maneira não planejada, impensada, os nossos estatutos de imagens, transformando-os. A estadia na escola, além de causar estranhamento em outros, acostumados com certa regularidade, também foi assinalada pelos estranhamentos dos licenciandos. Quem sabe isto fique implícito nas imagens.

\section{Imagens}

As imagens, a seguir, representam uma pequena parcela das mais de 100 fotos produzidas, as quais ficaram armazenadas no já citado grupo criado no facebook.com, com acesso restrito aos licenciandos. A partir desse escopo inicial, fizemos uma seleção das imagens mais significativas, eleitas pelo grupo, e criou-se uma página do site flickr.com (https://www.flickr.com/photos/146365663@N06) a fim de que ficassem acessíveis à comunidade escolar.

Com relação a uma devolutiva à instituição, além do site flickr.com, foi organizada uma apresentação aos professores, durante a reunião de planejamento na qual houve uma conversa acerca das suas impressões a respeito das imagens. Como última etapa, foram escolhidas nove fotos para serem impressas e expostas na escola. Reproduzimos abaixo algumas delas. 


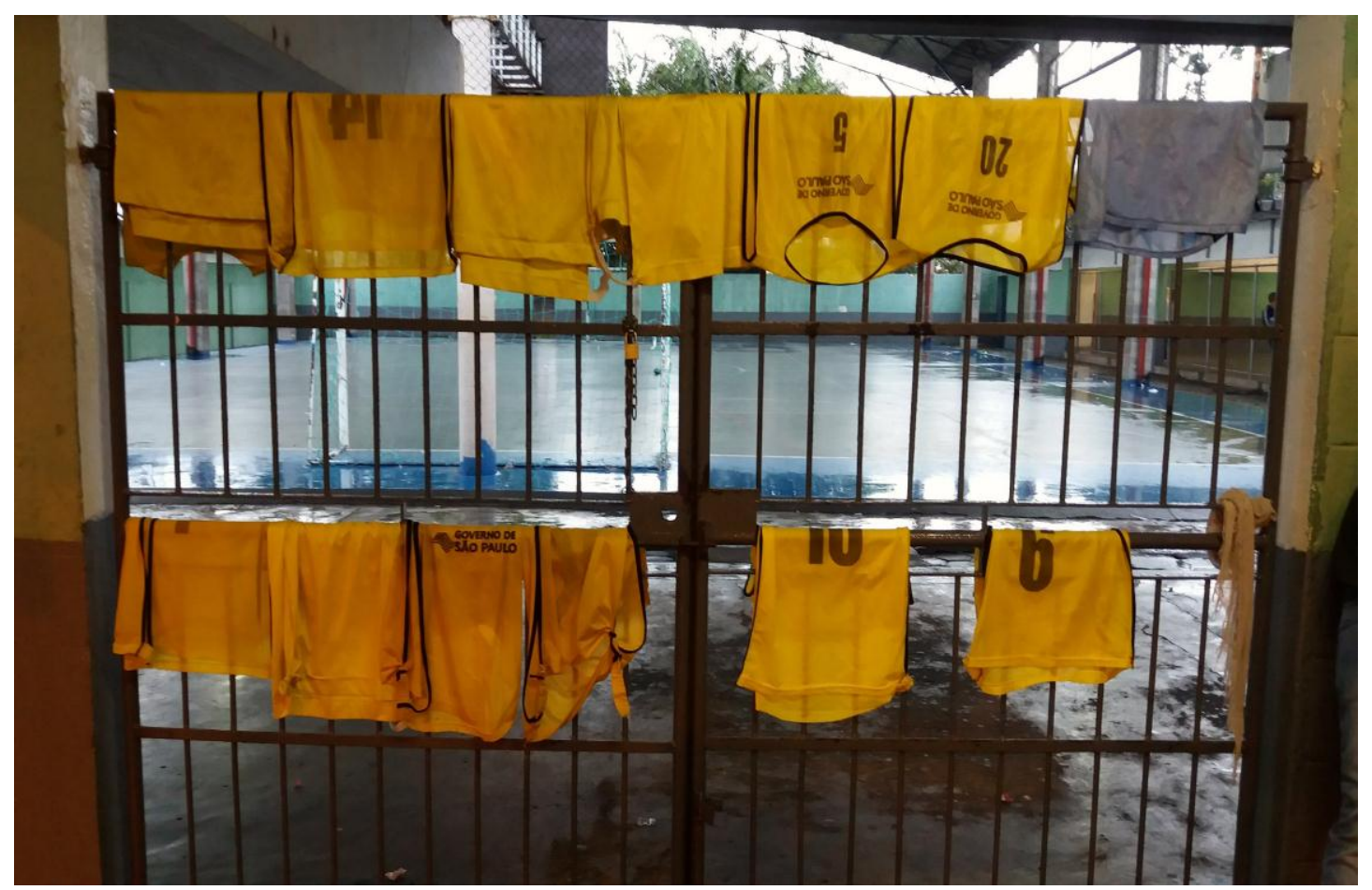

Foto 1: Uniformes esportivos.

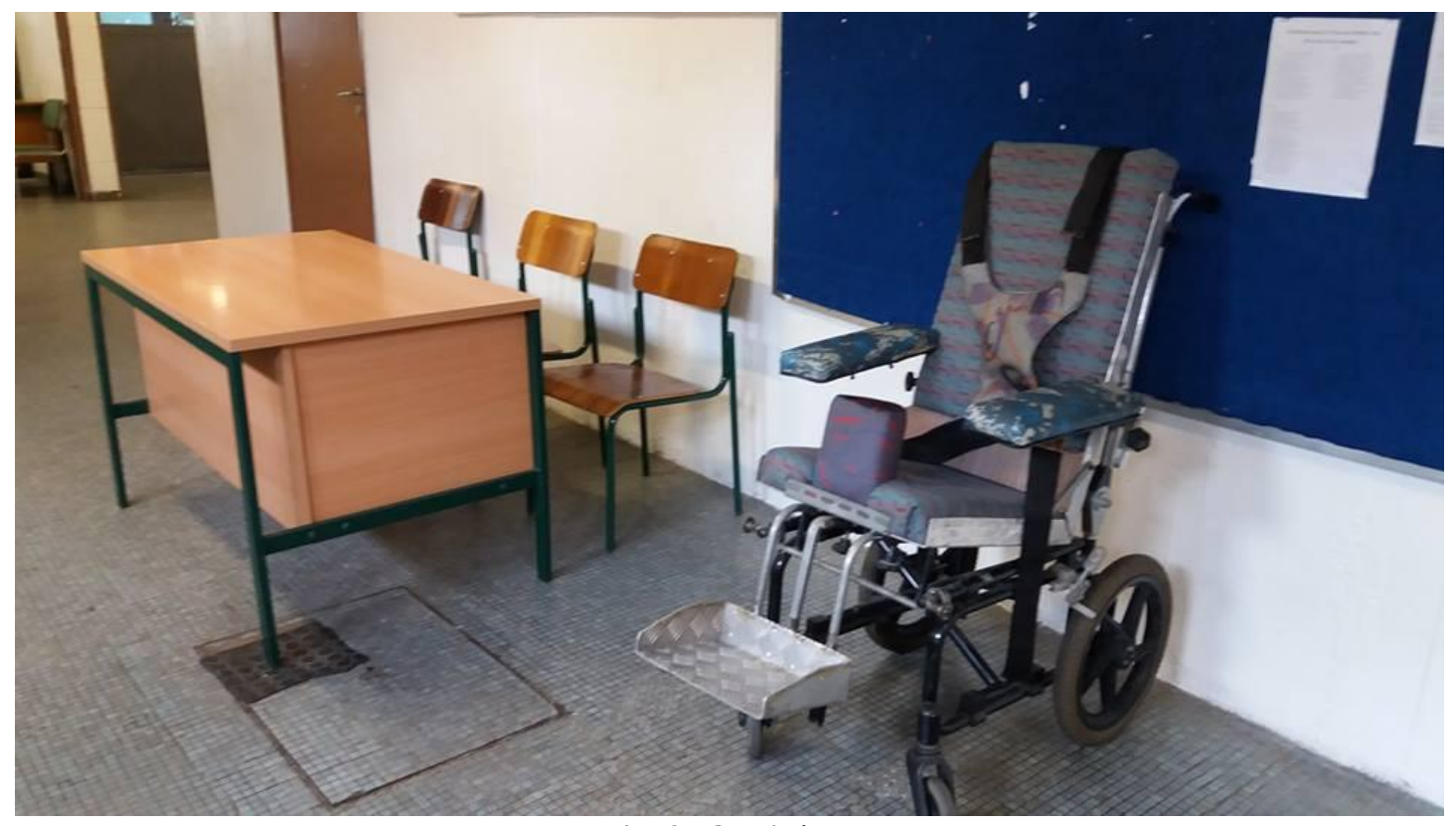

Foto 2: Cadeira. 


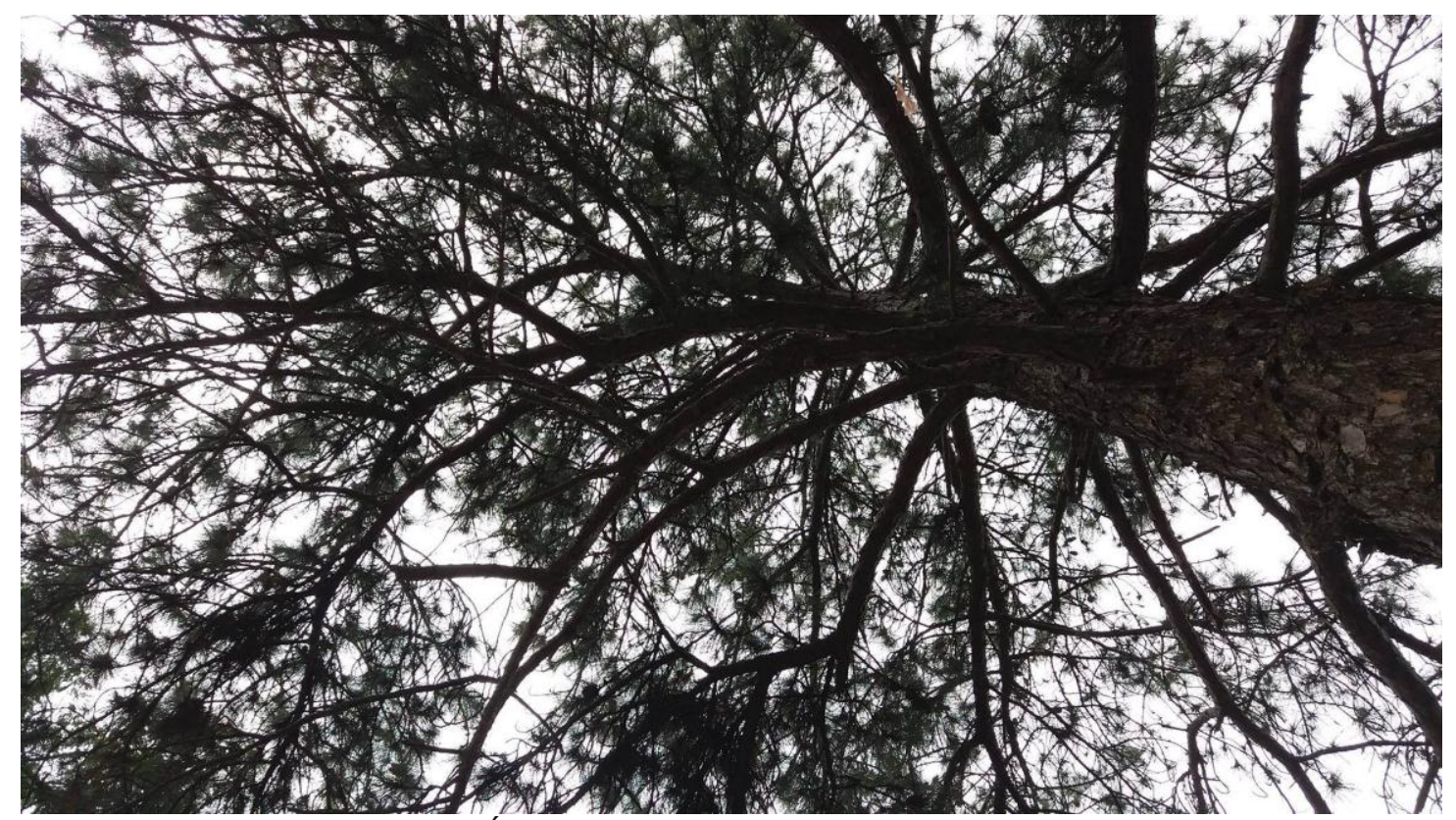

Foto 3: Árvore do jardim externo às salas.

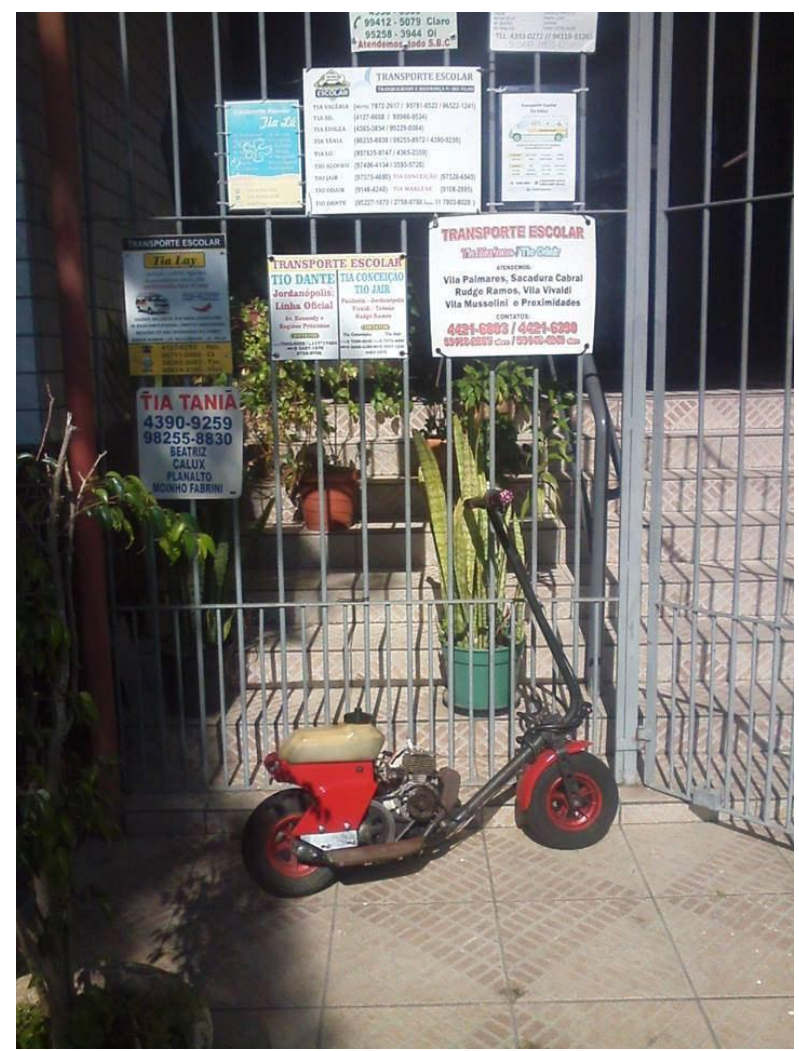

Foto 4: Meios de transporte. 


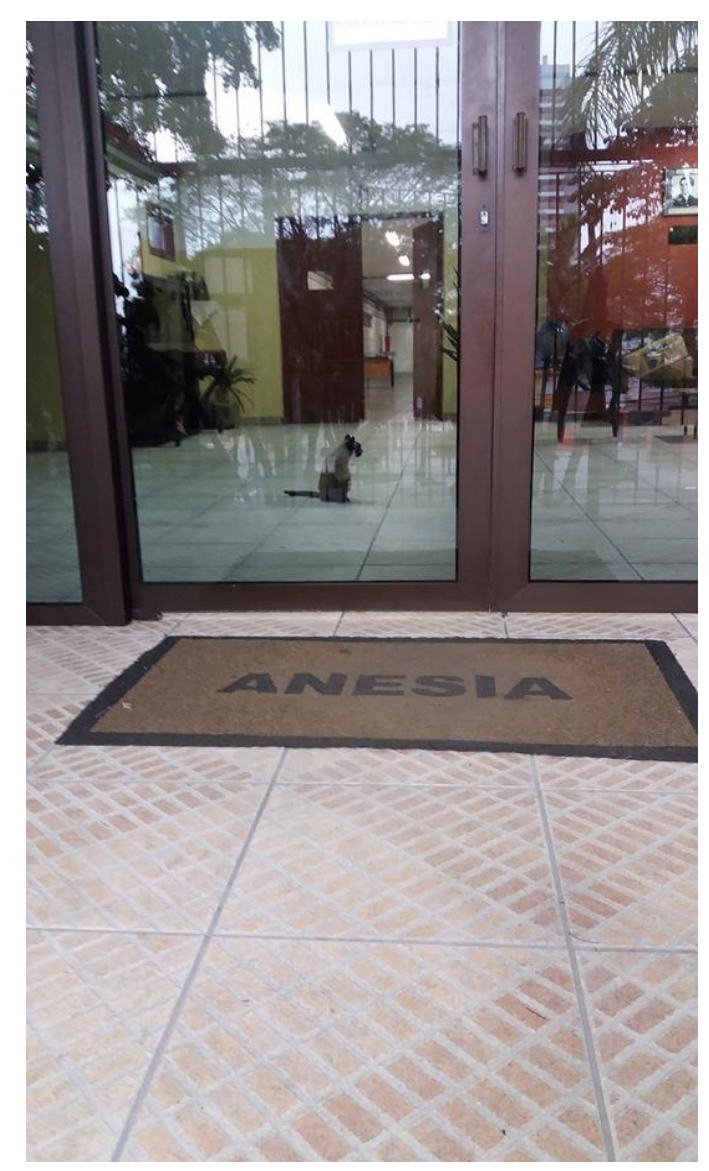

Foto 5: Entrada da escola e a gata de estimação.

Tais fotos foram escolhidas através do processo de reflexão sobre os clichês exatamente por não os representarem. Elas fogem deles, pois configuram momentos que caracterizam as singularidades da escola observada e não imagens que pudessem ser associadas a aspectos genéricos referentes a qualquer instituição educacional.

Desse modo, o impacto da grande sociabilidade, criada pelos jogos entre as classes e a constatação de sua característica positiva na construção de outros tipos de vivências na escola foram retratados pela foto 1, na qual podemos observar os uniformes secando à espera de novos jogos.

A foto 2 revela uma particularidade marcante da escola, qual seja, a convivência com alunos e alunas com deficiências, lá se tornando comum a presença de cadeiras de rodas, mas que, certamente, não é habitual no ambiente escolar. A foto 3 também aponta uma singularidade da escola e seus jardins. Antes, estes eram acessiveis pelas salas de aula, porém deixaram de sê-lo, o que faz da área um setor nunca visitado pelos alunos. Desse modo, Revista Digital de Ensino de Filosofia - Santa Maria - vol.3. n. 1 - jan./jun. 2017. 
talvez uma das formas de se saber como é o lugar, de conhecê-lo, seja pelas fotos.

As fotos 4 e 5 são da entrada para a secretaria da escola, destinada às questões administrativas. Consideramos bastante pitoresca a foto 4 que contrasta o profissionalismo das vans escolares com o patinete motorizado. Enquanto a foto 5 retrata as boas-vindas através de sua gata de estimação que passeia tranquilamente pelos seus setores administrativos.

São apenas cinco fotos que pretendem evidenciar que elas buscaram particularidades da escola observada se afastando fugindo dos clichês, como ambientes de confinamento com janelas gradeadas e portões com cadeados. Ou imagens clichês do papel uniformizante da escola, com carteiras enfileiradas. Ou ainda imagens de "bagunça" e descaso como carteiras quebradas e rabiscadas, aparelhos sanitários danificados, buracos e rachaduras nas paredes. Esses tipos de imagens foram produzidos durante este trabalho, porém o objetivo era gerar imagens que não repetissem, em um novo ambiente, aquelas genéricas que serviriam como uma espécie de reforço à ideia de que todas as escolas são assim. Nosso objetivo era tentar capturar algo que fosse particular à escola e acreditamos que tais fotos o fazem.

\section{Considerações finais}

O presente artigo foi construído a partir da proposta de estágio do professor orientador e relatórios dos licenciandos nela envolvidos. É relevante destacar que os alunos elaboraram um relatório final, individualmente, no qual refletiram a respeito da bibliografia debatida nas aulas de orientação, acrescentando as considerações próprias acerca da proposta desenvolvida, contendo ainda as observações do ambiente escolar.

Como enunciado no início do texto, pretendíamos transformar o estágio em uma pesquisa para potencializá-lo como formação dos licenciandos e na devolutiva à escola do que era produzido por eles. Nesse sentido, a construção do presente artigo é um dos resultados da pesquisa, abordando 
tudo aquilo que nela ainda existe de experimentação, além daquilo que gerou de conhecimento.

Desse modo, ainda que se configurando como uma prática incipiente, a produção de imagens desempenhou papel ativo na observação do ambiente escolar, pois aliou o desenvolvimento da crítica teórica com a produção prática. Referida crítica teórica se encontrava no mapeamento dos clichês comuns à observação das escolas como ambientes de confinamento, de controle rígido disciplinar, com hierarquias, burocracia, falta de interesse, entre outros. Entretanto fotografar para destacar o que se distancia tais imagens transformou-se em um exercício prático desafiador, porque os licenciandos produziam as imagens, compartilhavam com os colegas e juntos discutíamos o seu impacto diante do que estávamos teorizando.

A experiência de desnaturalizar o olhar, viciado pelos clichês na observação escolar, foi vivida com a produção de imagens desse ambiente, como um esforço de evidenciar as suas singularidades. Essa vivência possibilitou dois ganhos evidentes em relação ao estágio de observação tradicional: maior interação na devolutiva à escola do que foi elaborado pelos estagiários, na forma de exposição virtual no site flickr.com e física, com as fotos impressas e expostas na própria escola. O segundo ganho foi a experiência e formação nas técnicas envolvidas no processo, no sentido de que os licenciandos puderam fotografar, registrar em plataformas virtuais as suas fotos e organizar uma mostra delas. Certamente tal prática constitui-se um conhecimento válido para futuros docentes pensarem as suas práticas pedagógicas.

\section{Referências}

BARBOSA, Tatyana Mabel Nobre; NORONHA, Claudianny Amorim. Estágio supervisionado interdisciplinar, 11 v. Natal, RN: SEDIS, 2008.

COUTINHO, Eduardo; Documentário: Boca de lixo, disponível em: <https://www.youtube.com/watch?̨v=oZcT|C757mM>. 
DELEUZE, Gilles; GUATTARI, Félix, O que é a filosofia?, Rio de Janeiro: Editora 34, 2009;

A imagem-tempo: cinema 2. São Paulo, Brasiliense, 2005.

Conversações. São Paulo, Editora 34, 1992.

HEUSER, Ester Maria Dreher. Muros do estágio e da formação de professores de filosofia. SABERES, Natal-RN, v. 2, n.5, ago. 2010.

OHATA, M.(Org.). Eduardo Coutinho. São Paulo: Cosac Naify: SESC, 2014,

OLIVEIRA, Amurabi; BARBOSA, Vilma Soares Lima. Formação de professores em ciências sociais: Desafios e possibilidades a partir do Estágio e do PIBID, Revista Eletrônica Inter-Legere, Número 13, julho a dezembro de 2013.

PIMENTA, Selma Garrido e Lima, Maria Socorro Lucena. Estágio e docência. 6 ed. São Paulo, Cortez, 2011.

RIBETTO, Anelice;FILÉ, Valter. Uma experiência sobre produção imagética e alteridade. Revista educação em foco, Ano 17 - n. 23 - julho 2014 - p. 225-247.

TIBAU, Anderson. A prática de ensino numa perspectiva da imagens. Comunicação no encontro da Afirse, Natal, 2001. 